\title{
A novel backlash-adjustable and wear-compensable hourglass worm drive: computerized design, simulation of meshing and stress analysis
}

\author{
Yonghong CHEN*, Yan CHEN**, Wenjun LUO* and Guanghui ZHANG* \\ * State Key Laboratory of Mechanical Transmissions, Chongqing University \\ No. 174 Shazheng Street, Shapingba, Chongqing, P. R. China \\ E-mail: chenyonghongjc@163.com \\ ** Department of Printing and Media, Chongqing Business Vocational College \\ No.81 Daxuecheng Middle Road, Shapingba, Chongqing, P. R. China
}

Received 18 February 2016

\begin{abstract}
To satisfy the requirements of high accuracy and high-loading capacity, a novel precision-power hourglass worm drive characterizes with backlash-adjustable and wear-compensable is demonstrated. This hourglass worm drive is consisted of an involute helical beveloid (IHB) gear and a toroidal involute (TI) worm generated by the IHB gear tooth surface, and the material of IHB gear is bearing steel, as well as the material of TI worm is structural steel. For this hourglass worm drive, mathematical model is developed, basic equations are derived, and tooth contact analysis (TCA) is simulated by computerized calculation examples. Theory of backlash-adjustable and wear-compensable of this hourglass worm drive is derived. The high-loading capacity of this novel hourglass worm drive is confirmed by the TCA and stress analysis. This study is expected to provide a theoretical foundation for the future industrial application of this novel backlash-adjustable and wear-compensable hourglass worm drive.
\end{abstract}

Key words : Hourglass worm drive, Involute helical beveloid gear, Toroidal involute worm, Backlash-adjustable, Wear-compensable, Tooth contact analysis

\section{Introduction}

Worm drive is widely used to transmit motion and power at the shaft angle of $90^{\circ}$, and it can be divided into precision worm drive and power worm drive. The precision worm drive is characterized with high accuracy and is widely used for the accurate indexing of machine tools and instruments, such as the Wildhaber worm drive(Buckingham 1949; Wildhaber 1966), the dual-lead cylinder worm drive(Crosher 2002), the OTT worm drive(Crosher 2002) and double-roller hourglass enveloping worm drive(Deng, Wang et al. 2012). The power worm drive is characterized by high-loading capacity and is widely used for machine equipment in the fields of metallurgical and mine industry, such as the Niemann worm drive(Niemann 1965; Dudás 2000), the Hindley worm drive(Litvin and Fuentes 2004; Chen and Tsay 2009; Mohan and Shunmugam 2009), the planar double-enveloping hourglass worm drive(Zhang 1978; Crosher 2002), the dual-torus double-enveloping hourglass worm drive(Zhao and Zhang 2010; Zhao, Kong et al. 2011; Zhao, Kong et al. 2012) and the toroidal involute worm drive(Maki, Okamoto et al. 1995; Okamoto and Maki 1996; Wang, Zhan et al. 2002), as well as the crown worm drive(Chen, Zhang et al. 2013; Chen, Chen et al 2015). 
Implementing worm drive with complete non-backlash is neither reasonable nor practical. Therefore, lowbacklash is an important property of precision worm drive in many of today's applications. With the different loading and different operating condition, the ideally low-backlash of worm drive is also difference, and it requires the precision worm drive with the capability of backlash-adjustable. With the worn of tooth surface, the low-backlash of worm drive will be increase, and it requires the precision worm drive with the capability of wear-compensable. The conventional precision worm drive cannot meet those demands(Chen, Chen et al 2015). The dual-lead cylinder worm drive and the OTT worm drive can adjust the backlash and compensate the wearing, but there is only a few simultaneously contact teeth and cannot bearing the heavy loading. The Wildhaber worm drive and the double-roller hourglass enveloping worm drive are characterized with multitooth line contact, but they cannot compensate the wearing.

Recently, we proposed a precision-power hourglass worm drive, which is name as backlash-adjustable and wear-compensable hourglass worm drive. This novel worm drive is composed of an involute helical beveloid (IHB) gear and a toroidal involute (TI) worm generated by the IHB gear tooth surface. It belongs to the singleenveloping hourglass worm drive, which is characterized by multi-tooth line contact and has the performance of high load-carrying capacity. The IHB gear surface can be accurately manufactured by the involute gear profile grinding machine(B. Karpuschewski, H.-J. Knoche et al. 2008), and the TI worm surface can be accurately ground by a diamond dressing gear(Wang, Zhan et al. 2002) or a reformed hourglass worm grinder(Zhang and Li 2007; Sun, Lu et al. 2011). Based on the feature of that the helicoidal surface rotates about its axis is equal to the moves along its axial direction, the backlash can be adjusted and the wear can be compensated through moving the IHB gear along the axial direction. This hourglass worm drive is characterized by high accuracy and high-loading capacity, and can be widely used in artillery, follow-up systems, drive systems of NC, machine tools with gear drives and elevator traction machine.

In this study, the novel backlash-adjustable and wear-compensable hourglass worm drive is proposed. The mathematical equations of this hourglass worm drive are developed based on the gearing meshing theory. Based on the developed mathematical models, the computerized meshing simulations are carried out to examine the meshing performance. The feature of backlash-adjustable and wear-compensable is analyzed, and the feature of high-loading is confirmed by the tooth contact analysis and stress analysis.

\section{Generating of the hourglass worm drive}

The following analyses are based on the hypothesis: the IHB gear tooth surface $\Sigma^{1}$ is known, while the TI worm tooth surface $\Sigma^{2}$ is to be derived.

\subsection{Coordinate systems}

The coordinate systems of this hourglass worm drive are shown in Fig. 1. The fixed coordinate systems $\sigma_{\mathrm{m}}\left(o_{\mathrm{m}}: x_{\mathrm{m}}, y_{\mathrm{m}}, z_{\mathrm{m}}\right)$ and $\sigma_{\mathrm{n}}\left(o_{\mathrm{n}}: x_{\mathrm{n}}, y_{\mathrm{n}}, z_{\mathrm{n}}\right)$ indicate the initial position of the IHB gear and the TI worm, respectively. The movable coordinate system $\sigma_{1}\left(o_{1}: x_{1}, y_{1}, z_{1}\right)$ is rigidly connected to the IHB gear, while $\sigma_{2}\left(o_{2}: x_{2}, y_{2}, z_{2}\right)$ is 
rigidly connected to the TI worm. The IHB gear and the TI worm rotate about axes $z_{1}$ and $z_{2}$ with the angular velocity vectors $\omega_{1}$ and $\omega_{2}$, respectively. The rotating angles are $\varphi_{1}$ and $\varphi_{2}$ at some instant. The shortest distance between axes $z_{1}$ and axes $z_{2}$ is $a$.

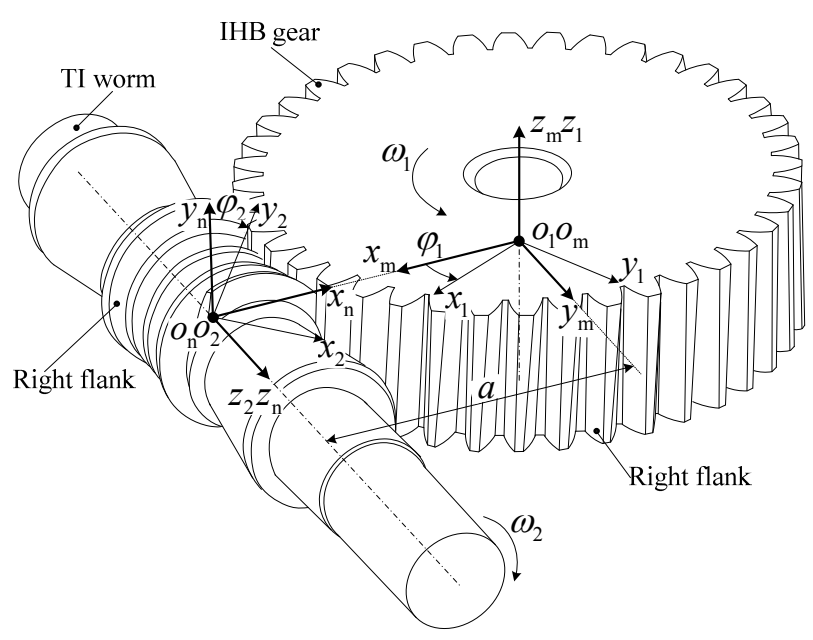

Fig. 1. Coordinate systems in worm drive

\subsection{IHB gear tooth surface equation}

As shown in Fig. 1, the IHB gear surface $\Sigma^{1}$ is actually an involute helical surface, and the helical angles of two flanks are unequal. The left flank equation of $\boldsymbol{r}_{1}^{\mathrm{L}}$ can be represented in coordinate system $\sigma_{\mathrm{m}}$ as follows:

$$
\begin{aligned}
& \boldsymbol{r}_{1}^{\mathrm{L}}(u, \theta)=\left[\begin{array}{lll}
x_{1}^{\mathrm{L}} & y_{1}^{\mathrm{L}} & z_{1}^{\mathrm{L}}
\end{array}\right] \\
& \quad=\left[\begin{array}{lll}
r_{\mathrm{b}} \cos (\delta+\theta-u)-r_{\mathrm{b}} u \sin (\delta+\theta-u) & r_{\mathrm{b}} \sin (\delta+\theta-u)+r_{\mathrm{b}} u \cos (\delta+\theta-u) & \frac{r_{\mathrm{b}}}{\cos \alpha \tan \beta_{\mathrm{L}}} \theta
\end{array}\right]
\end{aligned}
$$

The right flank equation of $\boldsymbol{r}_{1}{ }^{\mathrm{R}}$ can be represented in coordinate system $\sigma_{\mathrm{m}}$ as follows:

$$
\begin{aligned}
& \boldsymbol{r}_{1}^{\mathrm{R}}(u, \theta)=\left[\begin{array}{lll}
x_{1}^{\mathrm{R}} & y_{1}^{\mathrm{R}} & z_{1}^{\mathrm{R}}
\end{array}\right] \\
& \quad=\left[\begin{array}{lll}
r_{\mathrm{b}} \cos (\delta-\theta-u)-r_{\mathrm{b}} u \sin (\delta-\theta-u) & -r_{\mathrm{b}} \sin (\delta-\theta-u)-r_{\mathrm{b}} u \cos (\delta-\theta-u) & \frac{r_{\mathrm{b}}}{\cos \alpha \tan \beta_{\mathrm{R}}} \theta
\end{array}\right]
\end{aligned}
$$

where $u$ and $\theta$ are the surface parameters of $\Sigma^{1}, \delta$ is the half-angle of tooth on the base circle, $r_{\mathrm{b}}$ is the radius of base circle, $\alpha$ is the pressure angle of reference circle, $\beta_{\mathrm{L}}$ and $\beta_{\mathrm{R}}$ are the helical angles on the reference circle of the left flank and the right flank, respectively.

As shown in Fig. 1, the following condition about the helical angles should be satisfied:

$$
\beta_{\mathrm{L}}>\beta_{\mathrm{R}}
$$

\subsection{Meshing equation}

Without losing generality, it is possible to assume that the TI worm rotates with angular velocity $\omega_{1}=1 \mathrm{rad} / \mathrm{s}$, and then the IHB gear rotates with angular velocity $\omega_{2}=i_{12} \mathrm{rad} / \mathrm{s}$. According to the known tooth surface $\Sigma^{1}$, the relative velocity vector at the conjugate point of left flank can be represented in coordinate system $\sigma_{1}$ as follows: 


$$
\boldsymbol{v}_{12}^{\mathrm{L}}\left(u, \theta, \varphi_{1}\right)=\left[\begin{array}{lll}
z_{1}^{\mathrm{L}} \cos \varphi_{1}-i_{12} & -z_{1}^{\mathrm{L}} \sin \varphi_{1}+i_{12} & -x_{1}^{\mathrm{L}} \cos \varphi_{1}+y_{1}^{\mathrm{L}} \sin \varphi_{1}+a
\end{array}\right]
$$

and the relative velocity vector at the conjugate point of right flank can be represented in coordinate system $\sigma_{1}$ as follows:

$$
\boldsymbol{v}_{12}^{\mathrm{R}}\left(u, \theta, \varphi_{1}\right)=\left[\begin{array}{lll}
z_{1}^{\mathrm{R}} \cos \varphi_{1}-i_{12} & -z_{1}^{\mathrm{R}} \sin \varphi_{1}+i_{12} & -x_{1}^{\mathrm{R}} \cos \varphi_{1}+y_{1}^{\mathrm{R}} \sin \varphi_{1}+a
\end{array}\right]
$$

According to the differential geometry, the unit normal vector of the IHB gear surface $\Sigma^{1}$ on left flank can be represented in coordinate system $\sigma_{1}$ as following:

$$
\boldsymbol{n}_{1}^{\mathrm{L}}(u, \theta)=\left[\frac{\sin (\delta+\theta-u)}{\sqrt{1+\cos ^{2} \alpha \tan ^{2} \beta_{\mathrm{L}}}}-\frac{\cos (\delta+\theta-u)}{\sqrt{1+\cos ^{2} \alpha \tan ^{2} \beta_{\mathrm{L}}}}-\frac{\cos \alpha \tan \beta_{\mathrm{L}}}{\sqrt{1+\cos ^{2} \alpha \tan ^{2} \beta_{\mathrm{L}}}}\right]
$$

In the same way, the unit normal vector of the IHB gear surface $\Sigma^{1}$ on right flank can be represented in coordinate system $\sigma_{1}$ as following:

$$
\boldsymbol{n}_{1}^{\mathrm{R}}(u, \theta)=\left[-\frac{\sin (\delta-\theta-u)}{\sqrt{1+\cos ^{2} \alpha \tan ^{2} \beta_{\mathrm{R}}}}-\frac{\cos (\delta-\theta-u)}{\sqrt{1+\cos ^{2} \alpha \tan ^{2} \beta_{\mathrm{R}}}} \frac{\cos \alpha \tan \beta_{\mathrm{L}}}{\sqrt{1+\cos ^{2} \alpha \tan ^{2} \beta_{\mathrm{R}}}}\right]
$$

According to the gearing meshing theory(Wu and Luo 1985; Litvin and Fuentes 2004; Wu 2008), the tooth surface $\Sigma^{1}$ and $\Sigma^{2}$ are in tangency during the meshing process. Therefore, the following meshing condition equation should be satisfied:

$$
\Phi=v_{12} n_{1}=0
$$

Substituting $\boldsymbol{v}_{12}{ }^{\mathrm{L}}$ and $\boldsymbol{n}_{1}{ }^{\mathrm{L}}$ from Eqs. (4) and (6) into Eq. (8), the meshing function of the left flank can be obtained as following:

$$
\Phi^{\mathrm{L}}\left(u, \theta, \varphi_{1}\right)=M_{1}^{\mathrm{L}} \sin \left(\delta+\theta-u+\varphi_{1}\right)+M_{2}^{\mathrm{L}} \cos \left(\delta+\theta-u+\varphi_{1}\right)+M_{3}^{\mathrm{L}}
$$

where

$$
\begin{aligned}
& M_{1}^{\mathrm{L}}=\frac{r_{\mathrm{b}} u \cos ^{2} \alpha \tan ^{2} \beta_{\mathrm{L}}+r_{\mathrm{b}} \theta}{\cos \alpha \tan \beta_{\mathrm{L}} \sqrt{1+\cos ^{2} \alpha \tan ^{2} \beta_{\mathrm{L}}}}, \\
& M_{2}^{\mathrm{L}}=-\frac{r_{\mathrm{b}} \cos \alpha \tan \beta_{\mathrm{L}}}{\sqrt{1+\cos ^{2} \alpha \tan ^{2} \beta_{\mathrm{L}}}}, \\
& M_{3}^{\mathrm{L}}=\frac{a \cos \alpha \tan \beta_{\mathrm{L}}-i_{12}(\sin (\delta+\theta-u)+\cos (\delta+\theta-u))}{\sqrt{1+\cos ^{2} \alpha \tan ^{2} \beta_{\mathrm{L}}}} .
\end{aligned}
$$

In the same way, substituting $\boldsymbol{v}_{12}{ }^{\mathrm{R}}$ and $\boldsymbol{n}_{1}{ }^{\mathrm{R}}$ from Eqs. (5) and (7)into Eq. (9), after simplifying, the meshing function of the right flank can be obtained as following:

$$
\Phi^{\mathrm{R}}\left(u, \theta, \varphi_{1}\right)=M_{1}^{\mathrm{R}} \sin \left(\delta-\theta-u-\varphi_{1}\right)+M_{2}^{\mathrm{R}} \cos \left(\delta-\theta-u-\varphi_{1}\right)+M_{3}^{\mathrm{R}}
$$

where 


$$
\begin{aligned}
& M_{1}^{\mathrm{R}}=\frac{r_{\mathrm{b}} u \cos ^{2} \alpha \tan ^{2} \beta_{\mathrm{R}}-r_{\mathrm{b}} \theta}{\cos \alpha \tan \beta_{\mathrm{R}} \sqrt{1+\cos ^{2} \alpha \tan ^{2} \beta_{\mathrm{R}}}}, \\
& M_{2}^{\mathrm{R}}=-\frac{r_{\mathrm{b}} \cos \alpha \tan \beta_{\mathrm{R}}}{\sqrt{1+\cos ^{2} \alpha \tan ^{2} \beta_{\mathrm{R}}}}, \\
& M_{3}^{\mathrm{R}}=\frac{a \cos \alpha \tan \beta_{\mathrm{R}}+i_{12}(\sin (\delta-\theta-u)-\cos (\delta-\theta-u))}{\sqrt{1+\cos ^{2} \alpha \tan ^{2} \beta_{\mathrm{R}}}} .
\end{aligned}
$$

\subsection{TI worm tooth surface equation}

The TI worm tooth surface $\Sigma^{2}$ is enveloped by a series of IHB gear surface $\Sigma^{1}$. Based on Eqs. (1) and (9), and by coordinate transformation form $\sigma_{1}$ to $\sigma_{2}$, the TI worm surface equation of the left flank can be represented as following:

$$
\boldsymbol{r}_{2}^{\mathrm{L}}\left(u, \theta, \varphi_{1}\right)=\left(M_{12}\left[\begin{array}{ll}
\boldsymbol{r}_{1}^{\mathrm{L}} & 1
\end{array}\right]^{\mathrm{T}}\right)^{\mathrm{T}}, \quad \Phi^{\mathrm{L}}\left(u, \theta, \varphi_{1}\right)=0
$$

where

$$
M_{12}=\left[\begin{array}{cccc}
-\cos \varphi_{1} \cos \varphi_{2} & -\sin \varphi_{1} \cos \varphi_{2} & -\sin \varphi_{2} & a \cos \varphi_{2} \\
-\cos \varphi_{1} \sin \varphi_{2} & -\sin \varphi_{1} \sin \varphi_{2} & \cos \varphi_{2} & a \sin \varphi_{2} \\
-\sin \varphi_{1} & \cos \varphi_{1} & 0 & 0
\end{array}\right] .
$$

In the same way, using Eqs. (2) and (10), and by coordinate transformation form $\sigma_{1}$ to $\sigma_{2}$, the TI worm surface equation of the right flank can be represented as following:

$$
\boldsymbol{r}_{2}^{\mathrm{R}}\left(u, \theta, \varphi_{1}\right)=\left(M_{12}\left[\begin{array}{ll}
\boldsymbol{r}_{1}^{\mathrm{R}} & 1
\end{array}\right]^{\mathrm{T}}\right)^{\mathrm{T}}, \quad \Phi^{\mathrm{R}}\left(u, \theta, \varphi_{1}\right)=0
$$

\section{TCA of the hourglass worm drive}

\subsection{Contact lines}

Based on the Eqs. (1) and (9), the contact lines of the left flank of IHB gear surface $\Sigma^{1}$ and the left flank of TI worm surface $\Sigma^{2}$ can be calculated. The contact lines on the left flank of IHB gear surface $\Sigma^{1}$ can be represented as following:

$$
\boldsymbol{r}_{1}^{\mathrm{L}}(u, \theta), \quad \Phi^{\mathrm{L}}\left(u, \theta, \varphi_{1}\right)=0
$$

In the same way, based on the Eqs. (2) and (10), the contact lines of the right flank of IHB gear surface $\Sigma^{1}$ and the right flank of TI worm surface $\Sigma^{2}$ on can be determined. The contact lines on the right flank of IHB gear surface $\Sigma^{1}$ can be represented as following:

$$
r_{1}^{\mathrm{R}}(u, \theta), \quad \Phi^{\mathrm{R}}\left(u, \theta, \varphi_{1}\right)=0
$$

Eqs. (13) and (14) are considered as simultaneously, and the rotation angle $\varphi_{1}$ is considered as an input quantity, as well as the IHB gear tooth surface and the TI worm tooth surface are in-line contact at every instant. 


\subsection{Meshing limit line}

The meshing limit line is enveloped as a series of contact lines on IHB gear tooth surface $\Sigma^{1}(\mathrm{Wu}$ and Luo 1985). By taking the partial derivative of the Eq. (9) with time $t$, and the meshing limit function of the left flank can be obtained as following:

$$
\Phi_{t}^{\mathrm{L}}\left(u, \theta, \varphi_{1}\right)=\frac{\partial \Phi^{\mathrm{L}}}{\partial \varphi_{1}} \frac{\partial \varphi_{1}}{\partial t}=M_{1}^{\mathrm{L}} i_{12} \cos \left(\delta+\theta-u+\varphi_{1}\right)-M_{2}^{\mathrm{L}} i_{12} \sin \left(\delta+\theta-u+\varphi_{1}\right)
$$

where

$$
\begin{aligned}
& M_{1}^{\mathrm{L}}=\frac{r_{\mathrm{b}} u \cos ^{2} \alpha \tan ^{2} \beta_{\mathrm{L}}+r_{\mathrm{b}} \theta}{\cos \alpha \tan \beta_{\mathrm{L}} \sqrt{1+\cos ^{2} \alpha \tan ^{2} \beta_{\mathrm{L}}}}, \\
& M_{2}^{\mathrm{L}}=-\frac{r_{\mathrm{b}} \cos \alpha \tan \beta_{\mathrm{L}}}{\sqrt{1+\cos ^{2} \alpha \tan ^{2} \beta_{\mathrm{L}}}} .
\end{aligned}
$$

The meshing limit line on the left flank of IHB gear surface $\Sigma^{1}$ can be represented as:

$$
r_{1}^{\mathrm{L}}(u, \theta), \quad \Phi_{t}^{\mathrm{L}}\left(u, \theta, \varphi_{1}\right)=0
$$

In the same way, by taking the partial derivative of the Eq. (10) with time $t$, and the meshing limit function of the right flank can be obtained as following:

$$
\Phi_{t}^{\mathrm{R}}\left(u, \theta, \varphi_{1}\right)=\frac{\partial \Phi^{\mathrm{L}}}{\partial \varphi_{1}} \frac{\partial \varphi_{1}}{\partial t}=-M_{1}^{\mathrm{R}} i_{12} \cos \left(\delta-\theta-u-\varphi_{1}\right)+M_{2}^{\mathrm{R}} i_{12} \sin \left(\delta-\theta-u-\varphi_{1}\right)
$$

where

$$
\begin{aligned}
& M_{1}^{\mathrm{R}}=\frac{r_{\mathrm{b}} u \cos ^{2} \alpha \tan ^{2} \beta_{\mathrm{R}}-r_{\mathrm{b}} \theta}{\cos \alpha \tan \beta_{\mathrm{R}} \sqrt{1+\cos ^{2} \alpha \tan ^{2} \beta_{\mathrm{R}}}}, \\
& M_{2}^{\mathrm{R}}=-\frac{r_{\mathrm{b}} \cos \alpha \tan \beta_{\mathrm{R}}}{\sqrt{1+\cos ^{2} \alpha \tan ^{2} \beta_{\mathrm{R}}}} .
\end{aligned}
$$

The meshing limit line on the right flank of IHB gear surface $\Sigma^{1}$ can be represented as:

$$
r_{1}^{\mathrm{R}}(u, \theta), \quad \Phi_{t}^{\mathrm{R}}\left(u, \theta, \varphi_{1}\right)=0
$$

\subsection{Undercutting limit line}

The undercutting limit line is enveloped as a series of contact lines on the TI worm tooth surface $\Sigma^{2}$ (Wu and Luo 1985). According to the differential geometry and gear meshing theory(Litvin and Fuentes 2004; Wu 2008), the undercutting limit function on the left flank of TI worm tooth surface can be represented as following:

$$
\Psi^{\mathrm{L}}\left(u, \theta, \varphi_{1}\right)=\Phi_{t}^{\mathrm{L}}+\frac{1}{D^{\mathrm{L}}}\left[\frac{\partial \Phi^{\mathrm{L}}}{\partial u}\left(F^{\mathrm{L}} \frac{\partial \boldsymbol{r}_{1}^{\mathrm{L}}}{\partial \theta}-G^{\mathrm{L}} \frac{\partial \boldsymbol{r}_{1}^{\mathrm{L}}}{\partial u}\right)-\frac{\partial \Phi^{\mathrm{L}}}{\partial \theta}\left(E^{\mathrm{L}} \frac{\partial \boldsymbol{r}_{1}^{\mathrm{L}}}{\partial \theta}-F^{\mathrm{L}} \frac{\partial \boldsymbol{r}_{1}^{\mathrm{L}}}{\partial u}\right)\right] \boldsymbol{v}_{12}^{\mathrm{L}}
$$

where

$$
E^{\mathrm{L}}=r_{\mathrm{b}}{ }^{2} u^{2}, F^{\mathrm{L}}=-r_{\mathrm{b}}{ }^{2} u^{2}, G^{\mathrm{L}}=r_{\mathrm{b}}{ }^{2}\left(u^{2}+1+\sec ^{2} \alpha \cot ^{2} \beta\right), D^{\mathrm{L}}=r_{\mathrm{b}}{ }^{4} u^{2}\left(1+\sec ^{2} \alpha \cot ^{2} \beta\right) .
$$


The undercutting limit line on the left flank of TI worm surface $\Sigma^{2}$ can be represented as:

$$
\boldsymbol{r}_{2}^{\mathrm{L}}\left(u, \theta, \varphi_{1}\right)=\left(M_{12}\left[\begin{array}{ll}
\boldsymbol{r}_{1}^{\mathrm{L}} & 1
\end{array}\right]^{\mathrm{T}}\right)^{\mathrm{T}}, \quad \Phi^{\mathrm{L}}\left(u, \theta, \varphi_{1}\right)=0, \quad \Psi^{\mathrm{L}}\left(u, \theta, \varphi_{1}\right)=0
$$

In the same way, the undercutting limit function on the right flank of TI worm tooth surface can be represented as following:

$$
\Psi^{\mathrm{R}}\left(u, \theta, \varphi_{1}\right)=\Phi_{t}^{\mathrm{R}}+\frac{1}{D^{\mathrm{R}}}\left[\frac{\partial \Phi^{\mathrm{R}}}{\partial u}\left(F^{\mathrm{R}} \frac{\partial \boldsymbol{r}_{1}^{\mathrm{R}}}{\partial \theta}-G^{\mathrm{R}} \frac{\partial \boldsymbol{r}_{1}^{\mathrm{R}}}{\partial u}\right)-\frac{\partial \Phi^{\mathrm{R}}}{\partial \theta}\left(E^{\mathrm{R}} \frac{\partial \boldsymbol{r}_{1}^{\mathrm{R}}}{\partial \theta}-F^{\mathrm{R}} \frac{\partial \boldsymbol{r}_{1}^{\mathrm{R}}}{\partial u}\right)\right] \boldsymbol{v}_{12}^{\mathrm{R}}
$$

where

$$
E^{\mathrm{R}}=r_{\mathrm{b}}{ }^{2} u^{2}, \quad F^{\mathrm{R}}=-r_{\mathrm{b}}{ }^{2} u^{2}, G^{\mathrm{R}}=r_{\mathrm{b}}{ }^{2}\left(u^{2}+1+\sec ^{2} \alpha \cot ^{2} \beta\right), D^{\mathrm{R}}=r_{\mathrm{b}}{ }^{4} u^{2}\left(1+\sec ^{2} \alpha \cot ^{2} \beta\right) .
$$

The undercutting limit line on the right flank of TI worm tooth surface $\Sigma^{2}$ can be represented as:

$$
\boldsymbol{r}_{2}^{\mathrm{R}}\left(u, \theta, \varphi_{1}\right)=\left(M_{12}\left[\begin{array}{ll}
\boldsymbol{r}_{1}^{\mathrm{R}} & 1
\end{array}\right]^{\mathrm{T}}\right)^{\mathrm{T}}, \quad \Phi^{\mathrm{R}}\left(u, \theta, \varphi_{1}\right)=0, \quad \Psi^{\mathrm{R}}\left(u, \theta, \varphi_{1}\right)=0
$$

\subsection{Induced principal curvature}

According on the gearing meshing theory(Litvin and Fuentes 2004; Wu 2008), the meshing point normal vector of left flank can be represented as:

$$
\boldsymbol{a}_{n}^{\mathrm{L}}\left(u, \theta, \varphi_{1}\right)=\frac{1}{D^{\mathrm{L}}}\left[\frac{\partial \Phi^{\mathrm{L}}}{\partial u}\left(F^{\mathrm{L}} \frac{\partial \boldsymbol{r}_{1}^{\mathrm{L}}}{\partial \theta}-G^{\mathrm{L}} \frac{\partial \boldsymbol{r}_{1}^{\mathrm{L}}}{\partial u}\right)-\frac{\partial \Phi^{\mathrm{L}}}{\partial \theta}\left(E^{\mathrm{L}} \frac{\partial \boldsymbol{r}_{1}^{\mathrm{L}}}{\partial \theta}-F^{\mathrm{L}} \frac{\partial \boldsymbol{r}_{1}^{\mathrm{L}}}{\partial u}\right)\right]
$$

The meshing point induced principal curvature $k_{\rho}$ of left flank can be represented as:

$$
k_{\rho}^{\mathrm{L}}\left(u, \theta, \varphi_{1}\right)=-\frac{\left(\boldsymbol{a}_{n}^{\mathrm{L}}\right)^{2}}{\Psi^{\mathrm{L}}}
$$

Substituting $\Psi^{\mathrm{L}}$ and $\boldsymbol{a}_{\mathrm{n}}{ }^{\mathrm{L}}$ into Eq. (24) with the Eqs. (19) and (23), the meshing point induced principal curvature of left flank can be calculated.

In the same way, and the meshing point normal vector of right flank can be represented as:

$$
\boldsymbol{a}_{n}^{\mathrm{R}}\left(u, \theta, \varphi_{1}\right)=\frac{1}{D^{\mathrm{R}}}\left[\frac{\partial \Phi^{\mathrm{R}}}{\partial u}\left(F^{\mathrm{R}} \frac{\partial \boldsymbol{r}_{1}^{\mathrm{R}}}{\partial \theta}-G^{\mathrm{R}} \frac{\partial \boldsymbol{r}_{1}^{\mathrm{R}}}{\partial u}\right)-\frac{\partial \Phi^{\mathrm{R}}}{\partial \theta}\left(E^{\mathrm{R}} \frac{\partial \boldsymbol{r}_{1}^{\mathrm{R}}}{\partial \theta}-F^{\mathrm{R}} \frac{\partial \boldsymbol{r}_{1}^{\mathrm{R}}}{\partial u}\right)\right]
$$

The meshing point induced principal curvature $k_{\rho}$ of right flank can be represented as:

$$
k_{\rho}^{\mathrm{R}}\left(u, \theta, \varphi_{1}\right)=-\frac{\left(\boldsymbol{a}_{n}^{\mathrm{R}}\right)^{2}}{\Psi^{\mathrm{R}}}
$$

Substituting $\Psi^{\mathrm{R}}$ and $\boldsymbol{a}_{\mathrm{n}}^{\mathrm{R}}$ into Eq. (26) with the Eqs. (21) and (25), the meshing point induced principal curvature of right flank can be calculated.

\subsection{Sliding angle}

Based on the gearing meshing theory(Litvin and Fuentes 2004; Wu 2008), the sliding angle on the left flank can be represented as: 


$$
\theta_{v}^{\mathrm{L}}\left(u, \theta, \varphi_{1}\right)=\arcsin \left(\frac{\boldsymbol{a}_{n}^{\mathrm{L}} \boldsymbol{v}_{12}^{\mathrm{L}}}{\left|\boldsymbol{a}_{n}^{\mathrm{L}} \| \boldsymbol{v}_{12}^{\mathrm{L}}\right|}\right)
$$

Substituting $\boldsymbol{v}_{12}{ }^{\mathrm{L}}$ and $\boldsymbol{a}_{\mathrm{n}}{ }^{\mathrm{L}}$ into Eq. (27) with the Eqs. (4) and (23), the sliding angle on the left flank can be calculated.

Also the sliding angle on the right flank can be represented as:

$$
\theta_{v}^{\mathrm{R}}\left(u, \theta, \varphi_{1}\right)=\arcsin \left(\frac{\boldsymbol{a}_{n}^{\mathrm{R}} \boldsymbol{v}_{12}^{\mathrm{R}}}{\left|\boldsymbol{a}_{n}^{\mathrm{R}}\right|\left|\boldsymbol{v}_{12}^{\mathrm{R}}\right|}\right)
$$

Substituting $\boldsymbol{v}_{12}{ }^{\mathrm{R}}$ and $\boldsymbol{a}_{\mathrm{n}}{ }^{\mathrm{R}}$ into Eq. (28) with Eqs. (5) and (25), the sliding angle on the left flank can be calculated.

\section{Theory of backlash-adjustable and wear-compensable}

\subsection{Backlash-adjustable}

The characteristics of backlash-adjustable is based on the feature of helicoidal surface, which is that the helicoidal surface rotation about its axis is equal to the translational motion along its axial direction( $\mathrm{Wu} 2008)$.

On the basis of the left flank equation (1), this feature can be proofed as follows:

(i) Rotating this surface about its axis $\mathrm{Z}_{1}$ with angle $\phi$, and the new surface $\Sigma^{\mathrm{R}}$ can be represented as:

$$
r_{1}^{\mathrm{R}}(u, \theta)=\left[\begin{array}{l}
r_{\mathrm{b}} \cos \left(\delta_{1}-u+\theta-\phi\right)-r_{\mathrm{b}} u \sin \left(\delta_{1}-u+\theta-\phi\right) \\
r_{\mathrm{b}} \sin \left(\delta_{1}-u+\theta-\phi\right)+r_{\mathrm{b}} u \cos \left(\delta_{1}-u+\theta-\phi\right) \\
r_{\mathrm{b}}(\theta-\phi) /\left(\cos \alpha \tan \beta_{\mathrm{L}}\right)
\end{array}\right]^{\mathrm{T}}
$$

(ii) Moving this surface along its axial direction $z_{1}$ with displacement $h$, and the new surface $\Sigma^{\mathrm{M}}$ can be represented as:

$$
r_{1}^{\mathrm{M}}(u, \theta)=\left[\begin{array}{l}
r_{\mathrm{b}} \cos \left(\delta_{2}-u+\theta\right)-r_{\mathrm{b}} u \sin \left(\delta_{2}-u+\theta\right) \\
r_{\mathrm{b}} \sin \left(\delta_{2}-u+\theta\right)+r_{\mathrm{b}} u \cos \left(\delta_{2}-u+\theta\right) \\
r_{\mathrm{b}} \theta /\left(\cos \alpha \tan \beta_{\mathrm{L}}\right)-h
\end{array}\right]^{\mathrm{T}}
$$

(iii) Comparing the equations of surface $\Sigma^{\mathrm{R}}$ and surface $\Sigma^{\mathrm{M}}$ with Eqs. (29) and (30), when $\delta_{2}=\delta_{1}-\phi$ and $h=r_{\mathrm{b}}$ $\phi /\left(\cos \alpha \tan \beta_{\mathrm{L}}\right)$, the following equation can be obtained:

$$
r_{1}^{\mathrm{R}}(u, \theta)-\boldsymbol{r}_{1}^{\mathrm{M}}(u, \theta)=0
$$

Therefore, when $\delta_{2}=\delta_{1}-\phi$ and $h=r_{\mathrm{b}} \phi /\left(\cos \alpha \tan \beta_{\mathrm{L}}\right)$, the rotating surface $\Sigma^{\mathrm{R}}$ and the moving surface $\Sigma^{\mathrm{M}}$ is the same one.

Based on this helicoidal surface feature, the diagrammatic sketch of adjusting the backlash in this hourglass worm drive is shown in Fig. 2. Fig. 2(a) is the hourglass worm drive with backlash $\delta_{\mathrm{b}}$ on the reference circle of IHB gear, and Fig. 2(b) is that the IHB gear has moved along its axial direction $z_{1}$ with the displacement $h_{\mathrm{b}}$ and there is non-backlash in the hourglass worm drive. Line $L_{1}$ is the actual contact line between the TI worm tooth surface and the left flank tooth surface of IHB gear, line $L_{\mathrm{r} 1}$ is the theoretical contact line on the TI worm 
tooth surface, line $L_{\mathrm{r} 2}$ is the theoretical contact line on the right flank tooth surface of IHB gear, and the distance of line $L_{\mathrm{r} 1}$ and line $L_{\mathrm{r} 2}$ on the reference circle of IHB gear is $\delta_{\mathrm{b}}$. Line $L_{1}$ ' is the actual contact line between the TI worm tooth surface and the left flank tooth surface of IHB gear after the backlash adjusted, and line $L_{\mathrm{r}}$ is the actual contact line between the TI worm tooth surface and the right flank tooth surface of IHB gear after the backlash adjusted.

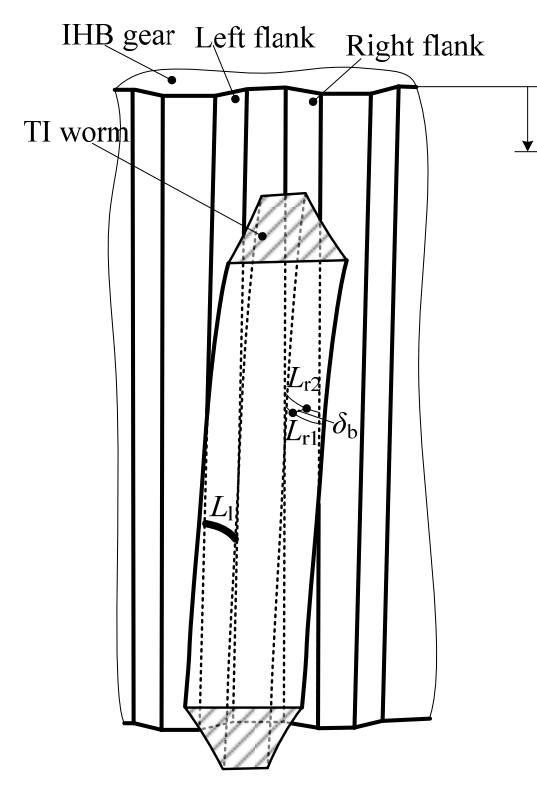

(a) Before adjusted

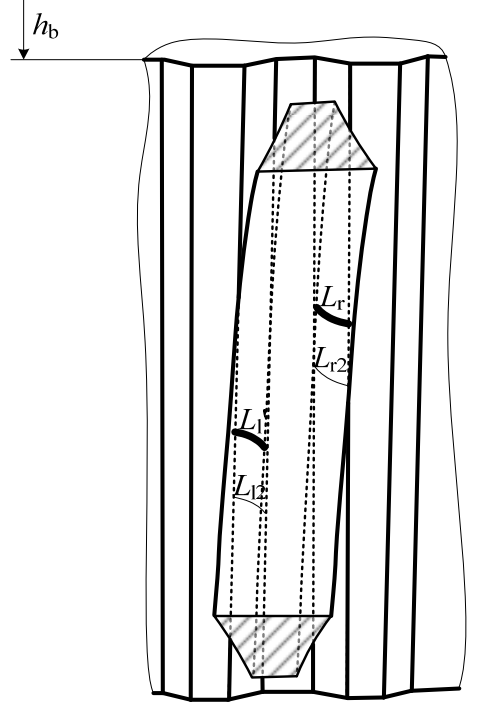

(b) After adjusted

Fig. 2. Adjusting theory of the backlash

Based on the feature of helicoidal surface and Eq. (31), though moving the IHB gear along its axial direction $z_{1}$ with the displacement $h_{\mathrm{b}}$, the rotating angle of the two tooth surfaces can be represented as:

$$
\begin{gathered}
\phi_{\mathrm{L}}=h_{\mathrm{b}} \cos \alpha \tan \beta_{\mathrm{L}} / r_{\mathrm{b}} \\
\phi_{\mathrm{R}}=-h_{\mathrm{b}} \cos \alpha \tan \beta_{\mathrm{R}} / r_{\mathrm{b}}
\end{gathered}
$$

where $\phi_{\mathrm{L}}$ and $\phi_{\mathrm{R}}$ are the rotating angle of the left flank tooth surface and the right flank tooth surface, respectively.

According to the geometric relationship in Fig. 2, the follow equation can be obtained:

$$
\begin{aligned}
\delta_{\mathrm{b}} & =r_{2}\left(\phi_{\mathrm{L}}+\phi_{\mathrm{R}}\right) \\
& =r_{2}\left(h_{\mathrm{b}} \cos \alpha \tan \beta_{\mathrm{L}} / r_{\mathrm{b}}-h_{\mathrm{b}} \cos \alpha \tan \beta_{\mathrm{R}} / r_{\mathrm{b}}\right) \\
& =h_{\mathrm{b}}\left(\tan \beta_{\mathrm{L}}-\tan \beta_{\mathrm{R}}\right)
\end{aligned}
$$

From Eq. (34) we also can be found that: i) When $\beta_{\mathrm{L}}=\beta_{\mathrm{R}}$, this hourglass worm drive cannot adjust the backlash and it is the conventional TI worm drive; ii) When $\beta_{\mathrm{L}}>\beta_{\mathrm{R}}$, the backlash of hourglass worm drive can be adjusted by moving the IHB gear along the direction as shown in Fig. 2; iii) When $\beta_{\mathrm{L}}<\beta_{\mathrm{R}}$, the backlash of hourglass worm drive can be adjusted by moving the IHB gear along the reverse direction as shown in Fig. 2.

Therefore, the backlash of this novel hourglass worm drive can be adjusted by moving the IHB gear along 
its axial direction. So the backlash can be adjusted to non-backlash or little backlash.

\subsection{Wear-compensable}

The characteristics of wear-compensable are based on the materials of IHB gear and TI worm. Because of the IHB gear material is quenched bearing steel and the TI worm material is quenched and tempered structural steel, the tooth surface of TI worm will be worn while the tooth surface of IHB gear will be not.

The diagrammatic sketch of compensating the wear in this hourglass worm drive is shown in Fig. 3. Fig. 3(a) shows the hourglass worm drive with non-backlash. Fig. 3(b) shows the hourglass worm drive after normal operation, and the tooth surface of TI worm has been worn while the tooth surface of IHB gear has not been worn, as well as the backlash on the reference circle of IHB gear is $\delta_{\mathrm{s}}$. Fig. 3(c) represents the IHB gear when it has moved along its axial direction $z_{1}$ with the displacement $h_{\mathrm{s}}$ and there is non-backlash in the hourglass worm drive. Line $L_{1}$ is the actual contact line between the TI worm tooth surface and the left flank tooth surface of IHB gear, and line $L_{\mathrm{r}}$ is the actual contact line between the TI worm tooth surface and the right flank tooth surface of IHB gear. Line $\mathrm{L}_{\mathrm{r}}$ is theoretical contact line on the TI worm tooth surface after normal operation, and line $L_{\mathrm{r} 2}$ is theoretical contact line on the right flank tooth surface of IHB gear, as well as the distance of line $L_{\mathrm{r} 1}$ and line $L_{\mathrm{r} 2}$ on the reference circle of IHB gear is $\delta_{\mathrm{s}}$. Furthermore, the wear quantity of hourglass worm drive is $\delta_{\mathrm{s}}$. Line $L_{1}$, is the actual contact line between the TI worm tooth surface and the left flank tooth surface of IHB gear after the wear compensated, and line $L_{\mathrm{r}}$, is the actual contact line between the TI worm tooth surface and the right flank tooth surface of IHB gear after the wear compensated.

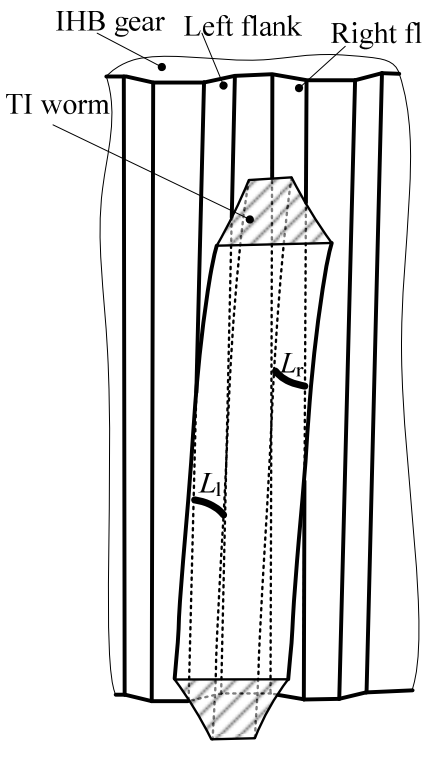

(a) Before worn

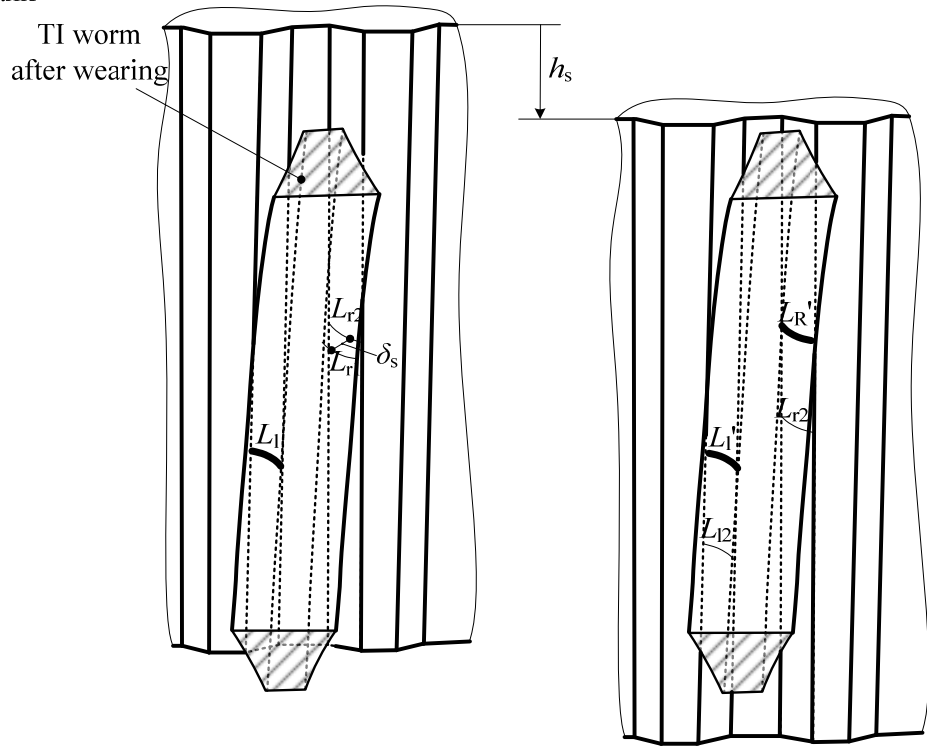

(c) After compensated

Fig. 3. Compensating theory of the worn

The moving displacement $h_{\mathrm{s}}$ can be calculated as following:

$$
h_{\mathrm{s}}=\frac{\delta_{\mathrm{s}}}{\left(\tan \beta_{\mathrm{L}}-\tan \beta_{\mathrm{R}}\right)}
$$




\section{Numerical examples and discussion}

Four examples are considered in this section. These examples have the same design parameters except the helical angle, as shown in Tab. 1.

Tab. 1. Design parameters of worm drive

\begin{tabular}{|c|c|c|c|c|}
\hline \multirow{2}{*}{ Parameters } & \multicolumn{4}{|c|}{ Examples } \\
\hline & A & $\mathrm{B}$ & $\mathrm{C}$ & $\mathrm{D}$ \\
\hline Center distance, $a(\mathrm{~mm})$ & 240 & & & \\
\hline Numbers of the TI worm threads, $Z_{1}$ & 1 & & & \\
\hline Numbers of the IHB gear teeth, $Z_{2}$ & 81 & & & \\
\hline Thread direction of worm & Right & & & \\
\hline Transverse module of the IHB gear, $m_{\mathrm{t}}(\mathrm{mm})$ & 5 & & & \\
\hline Pressure angle of reference circle, $\alpha\left({ }^{\circ}\right)$ & 20 & & & \\
\hline Helical angle on the reference circle of left flank, $\beta_{\mathrm{L}}\left({ }^{\circ}\right)$ & 2 & 3 & 4 & 8 \\
\hline Helical angle on the reference circle of right flank, $\beta_{\mathrm{R}}\left({ }^{\circ}\right)$ & 1 & 2 & 3 & 7 \\
\hline Radius of the basic circle, $r \mathrm{~b}(\mathrm{~mm})$ & 190.288 & & & \\
\hline Half-angle of tooth on the base circle, $\delta\left({ }^{\circ}\right)$ & 2.36 & & & \\
\hline Length of the TI worm, $l(\mathrm{~mm})$ & 150 & & & \\
\hline Width of the IHB gear, $b(\mathrm{~mm})$ & 80 & & & \\
\hline
\end{tabular}

\subsection{Meshing area and contact lines}

The contact lines and the meshing limit line are observed on IHB gear tooth surface $\Sigma^{1}$, the abscissa $z_{1}$ and $r_{1}$ ordinate are considered, here $\left(r_{1}\right)^{2}=\left(x_{1}\right)^{2}+\left(y_{1}\right)^{2}$. Based on Eqs. (13) and (16), lines on the left flank of surface $\Sigma^{1}$ can be simulated by computer and projected on the plane $z_{1} o_{1} r_{1}$, as shown in Fig. 4.

From Fig. 4, it can be found that there are two meshing limit lines exist in surface $\Sigma^{1}$. Meshing limit lines divide surface $\Sigma^{1}$ into three areas, which are named as the actual meshing area, non-meshing area and theoretical meshing area. The actual meshing area consists of a family of contact lines, the non-meshing area is the area between the two meshing limit lines, and the theoretical meshing area is an imaginary meshing area.

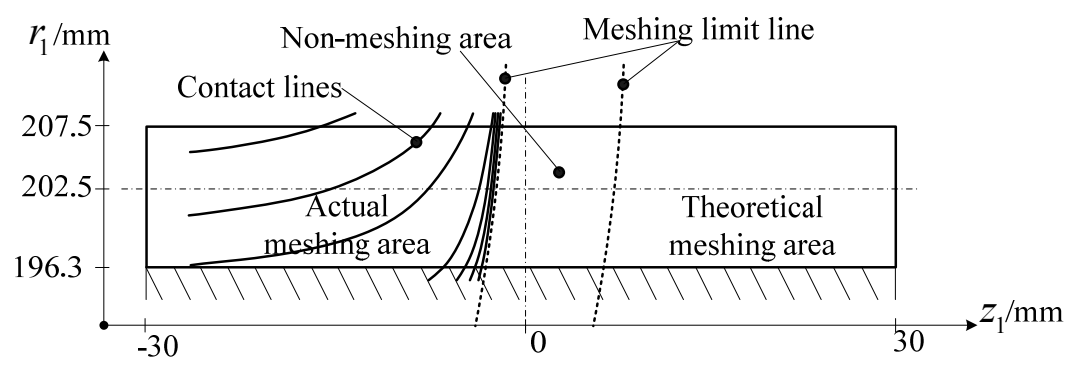

Fig. 4. Meshing areas on the surface $\Sigma^{1}$ 
The meshing limit line and the contact lines on both left and right flanks of surface $\Sigma^{1}$ are simulated for each example and projected on the plane $z_{1} o_{1} r_{1}$, as shown in Fig. 5.

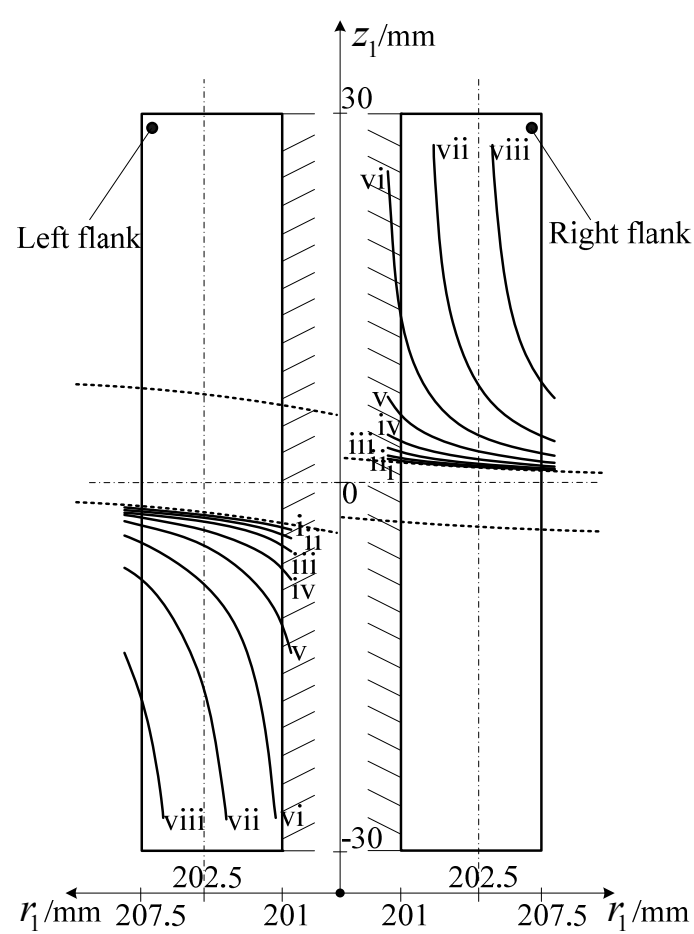

(a) Example A

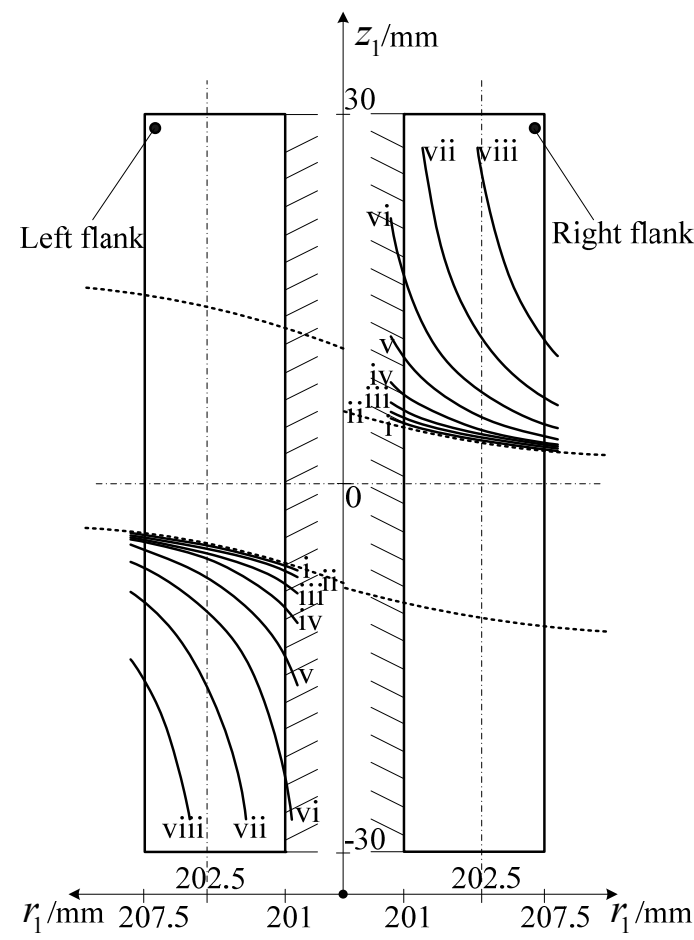

(c) Example C

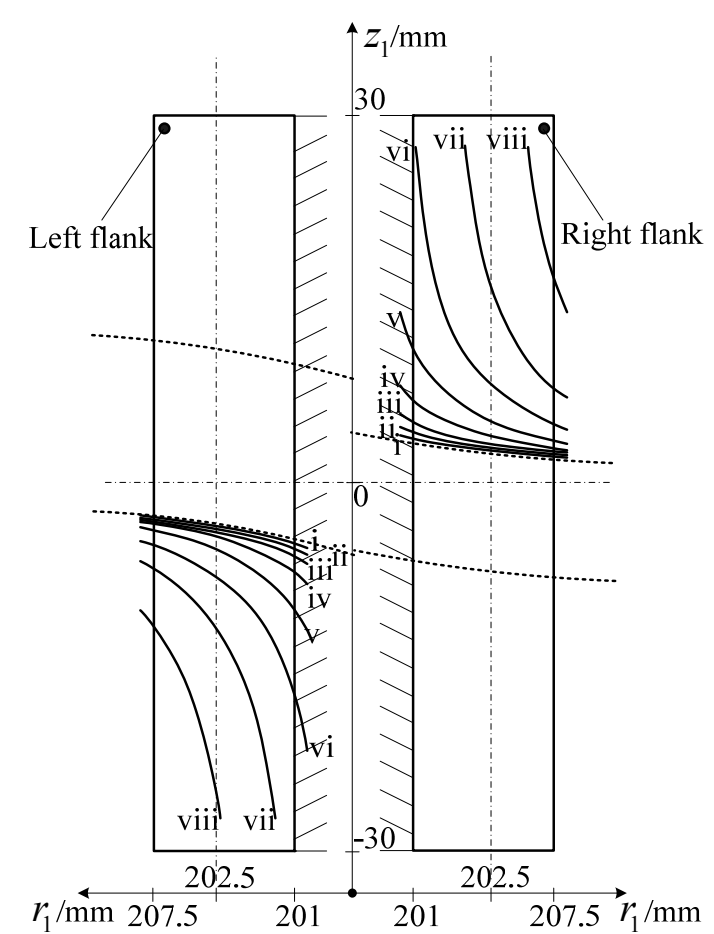

(b) Example B

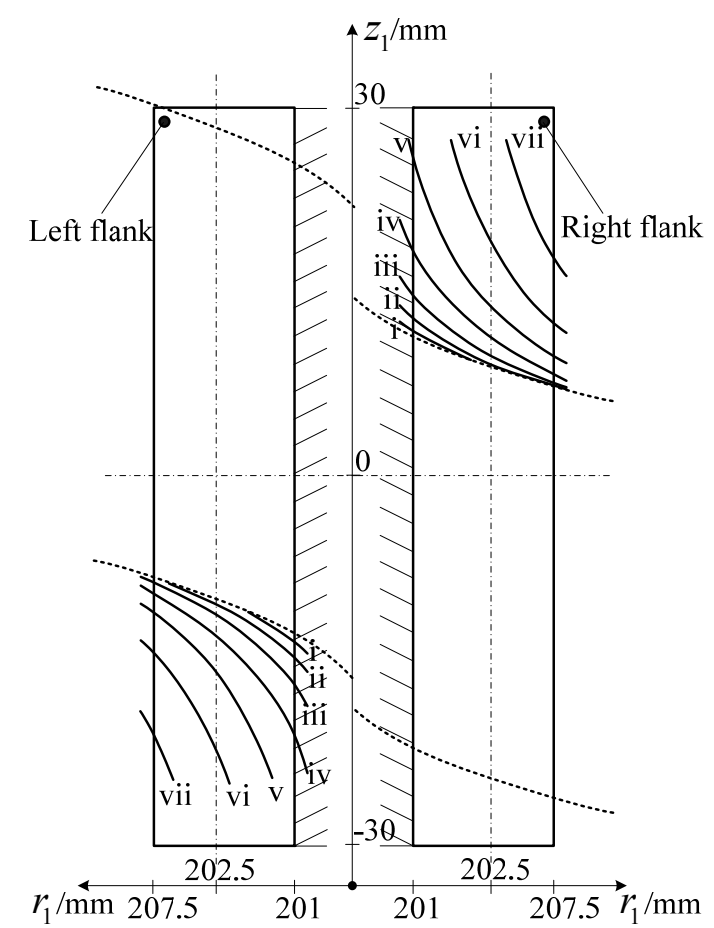

(d) Example D

Fig. 5. Contact lines on surface $\Sigma^{1}$ 
In Fig. 5, the contact lines on the conjugate surface are named from No. i to No. viii, the contact line No. i is on the exit of actual meshing area, as well as the contact line No. viii is on the entrance. The D-value of rotating angle $\varphi_{2}$ between each two contact lines is $2 \pi$. It can be found that the actual meshing area decreased and the non-meshing area increased with the increasing of helical angle, and the simultaneously contact teeth also decreases when the helical angle becomes bigger. The actual meshing area on the left flank is above the middle plane, and that on the right flank is under the middle plane. With the small helical angle, the actual meshing area always near the middle plane of this hourglass worm drive.

Obviously, the smaller of helical angle, and the better meshing performance of this novel hourglass worm drive.

\subsection{Local meshing quality}

For each example, three calculation points are considered on the contact line, and they are the intersection point of contact line and addendum circle, reference circle, root circle. The local meshing quality may be obtained at the calculation points by using the Eqs. (24), (26), (27) and (28). The average value of induced principal curvature and sliding angle on each contact line are shown in Fig. 6 and Fig. 7.

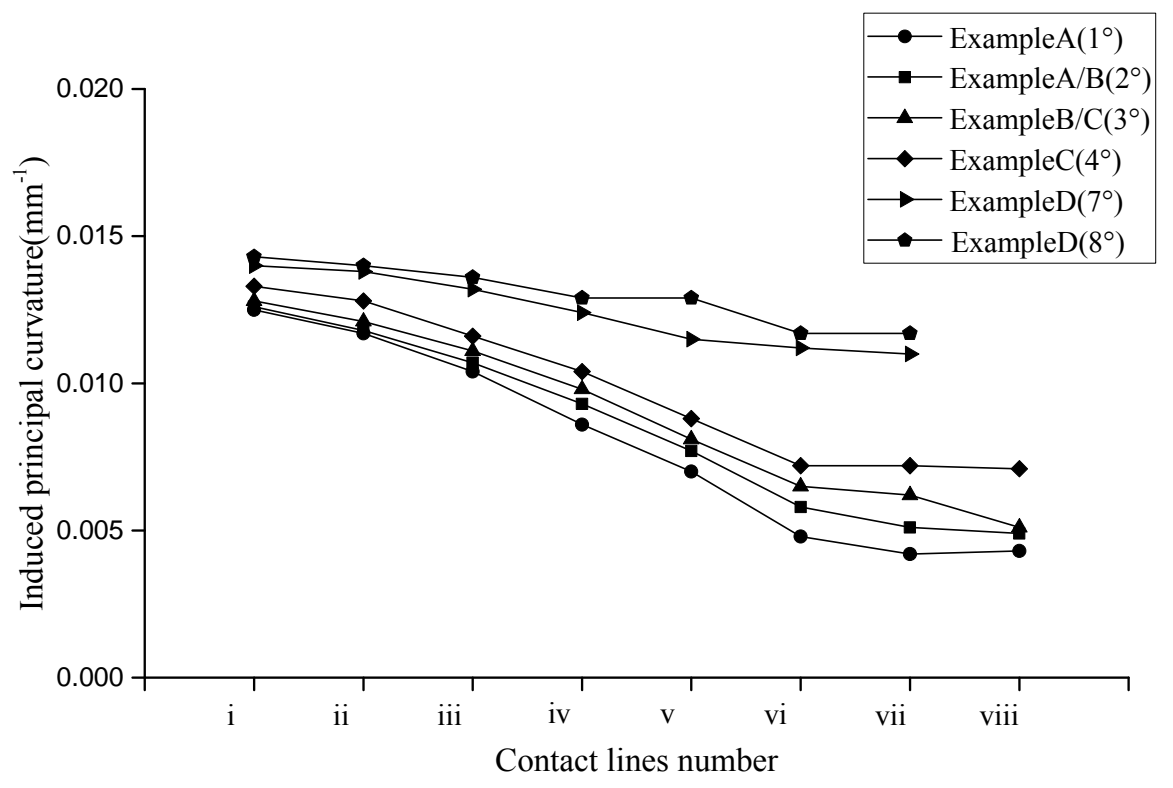

Fig. 6. The induced principal curvature in each example 


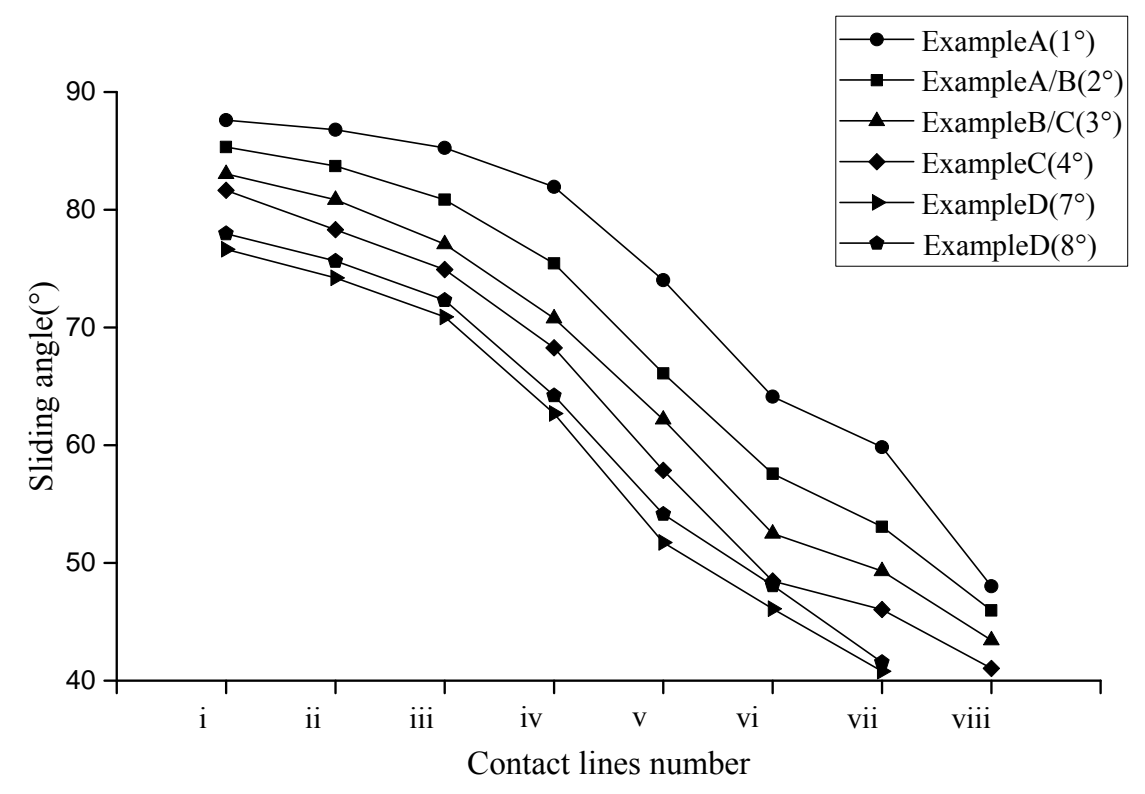

Fig. 7. The sliding angle in each example

From Fig. 6 and Fig. 7, it can be found that the induced principal curvatures on the exit are smaller than those on the entrance, and the sliding angles on the entrance are closer to $90^{\circ}$. These results indicate that the meshing area exit has a superior load-carrying capacity, and the meshing area entrance has a more ideal lubrication condition.

It can also be found that the induced principal curvature increased and sliding angle decreased with the increasing of helical angle. That is to say, the smaller of helical angle and the better of local meshing quality, so the helical angle plays an important role in the local meshing quality.

However, the obtained local meshing quality data illustrate that this hourglass worm drive is with the high load-carrying capacity and good lubrication condition. Because of the different helical angles, the local meshing quality on the right flank is more superior to that on the left flank.

\subsection{Stress analysis}

Stress analysis has been performed on this hourglass worm drive for the purpose of investigation of bearing contact and contact stress. The stress analysis is based on the application of the finite element method by a general purpose computer program(Fuentes, Jose et al. 2011; Fuentes, Ramon et al. 2014).

By applying the computer program and the IHB gear tooth surface equations Eqs (1) and (2), as well as the TI worm tooth surface equations Eqs (11) and (12), the three-dimensional graphic of the hourglass worm drive with the design parameters of example A can be shown in Fig. 8. 


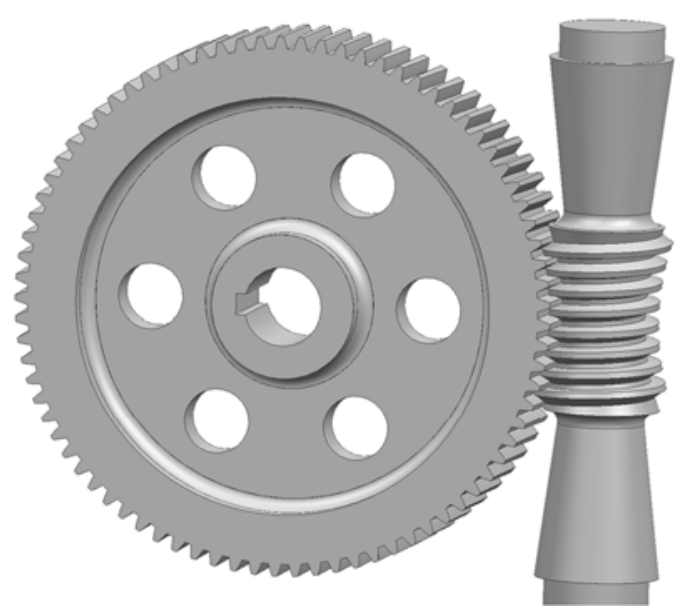

Fig. 8. Three-dimensional computer graphic of this hourglass worm drive

Based on the three-dimensional model, the finite element models are accomplished as shown in Fig. 9.

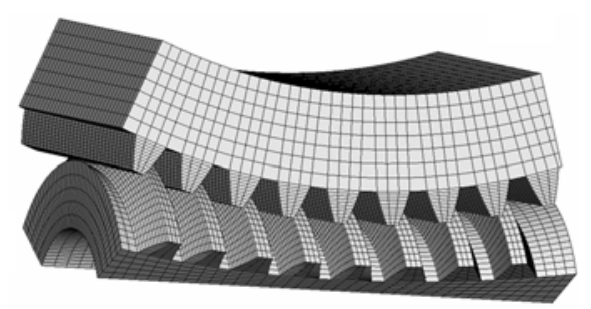

Fig. 9. Finite element model

Boundary conditions of the finite element models require special considerations in case of hourglass worm drives with respect to helical or spiral bevel gear drives. This novel hourglass worm drives boundary conditions are set as follows (see Fig. 10):

(i) IHB gear is considered at rest by definition of a rigid surface on the gear rim called rigid surface I, which is fixed;

(ii) A rigid surface, called rigid surface II, is defined on the rim of the TI worm. There is just one degree of freedom for the rigid surface II corresponding to the tangential remote with axis $z_{2}$. A moment $\mathrm{M}_{2}$ is applied at the rigid surface II. In this way, the moment is transferred to the TI worm model through its rigid surface while IHB gear is held at rest.

(iii) Contact surfaces are automatically defined on TI worm and IHB gear teeth for application of the contact algorithm. 


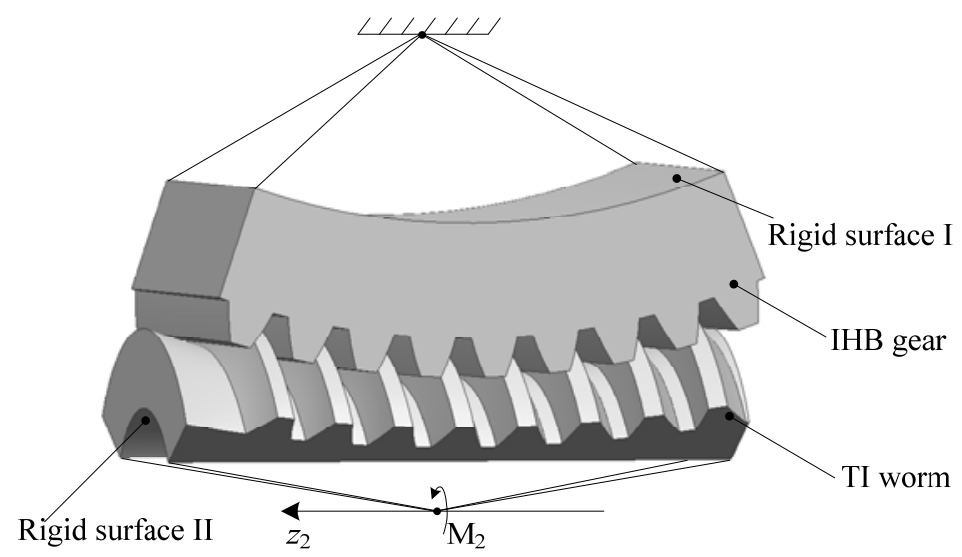

Fig. 10. Boundary conditions for stress analysis

The definition of the contact surfaces necessary for the finite element analysis is accomplished automatically, and the CONTA 174 has been used for the contact surface on the TI worm tooth surface, as well as the TARGE 170 has been used for the target surface in the IHB gear tooth surface. The total number of elements is 71290 with 96144 nodes. TI worm material is structural steel with the properties of Young's Modulus $\mathrm{E}=2.07 \times 10^{11}$ $\mathrm{Pa}$ and Poisson's ratio 0.3, while IHB gear material is bearing steel with the properties of Young's Modulus E $=2.08 \times 10^{11} \mathrm{~Pa}$ and Poisson's ratio 0.29. A torque of $100 \mathrm{Nm}$ has been applied to the TI worm on each analysis.

Fig. 11 shows the contact status on the IHB gear tooth surfaces of each example in Tab. 1. In Fig. 11, the brown area means the sliding area between the IHB gear tooth surfaces and the TI worm tooth surface, and the yellow area means the near contacting area between the IHB gear tooth surfaces and the TI worm tooth surface, as well as the blue area means the far contacting area between the IHB gear tooth surfaces and the TI worm tooth surface.

In Fig. 11, it shows that there is line contact on each couple tooth between the IHB gear tooth surfaces and the TI worm tooth surface, and the actual contact lines decreases when the helical angle becomes bigger, as well as the actual contact lines in accordance with the theoretical contact lines in Fig. 5. It also can be found that the near contacting area on the exit tooth surface is bigger than that on the entrance tooth surface, and it in accordance with the induced principal curvature in Fig. 6. Because of that, the smaller of the induced principal curvature, the closer of contacting area between the IHB gear tooth surfaces and the TI worm tooth surface(Litvin and Fuentes 2004).

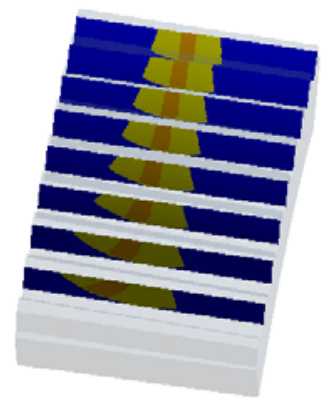

(a) Example A

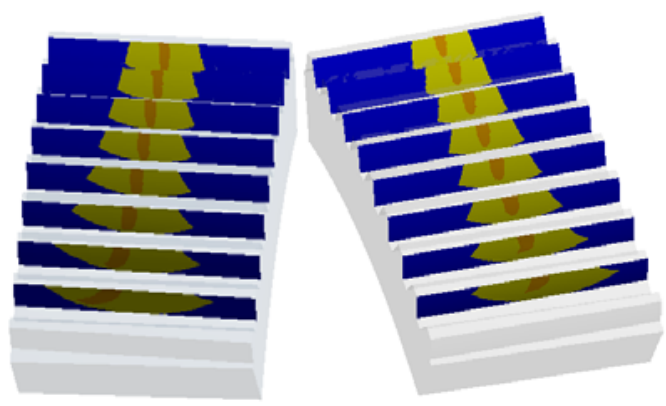

(b) Example B 

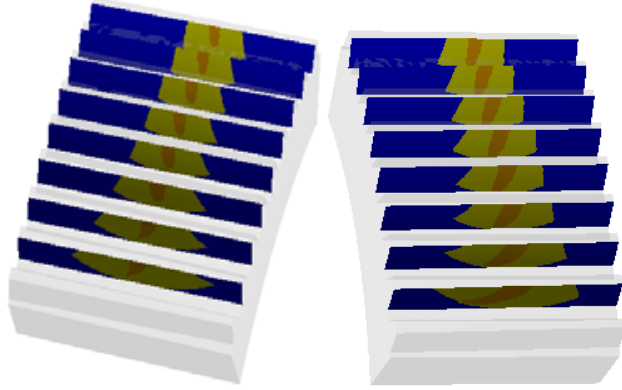

(c) Example $\mathrm{C}$
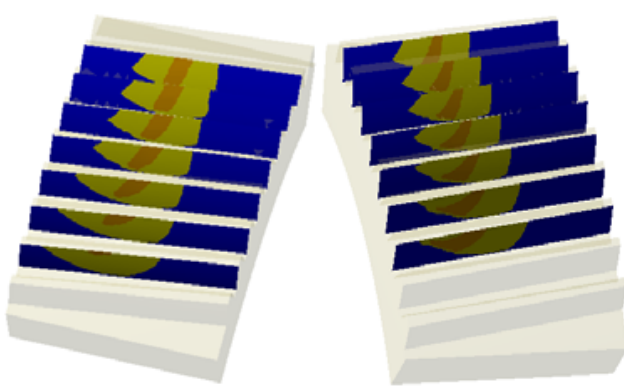

(d) Example D

Fig. 11. Contact status on surface $\Sigma^{1}$

The biggest contact pressure on every couple contact tooth of each example are shown in Fig. 12. It can be found that the biggest contact pressure on the entrance tooth surface is bigger than that on the exit tooth surface, and it also in accordance with the induced principal curvature in Fig. 6.

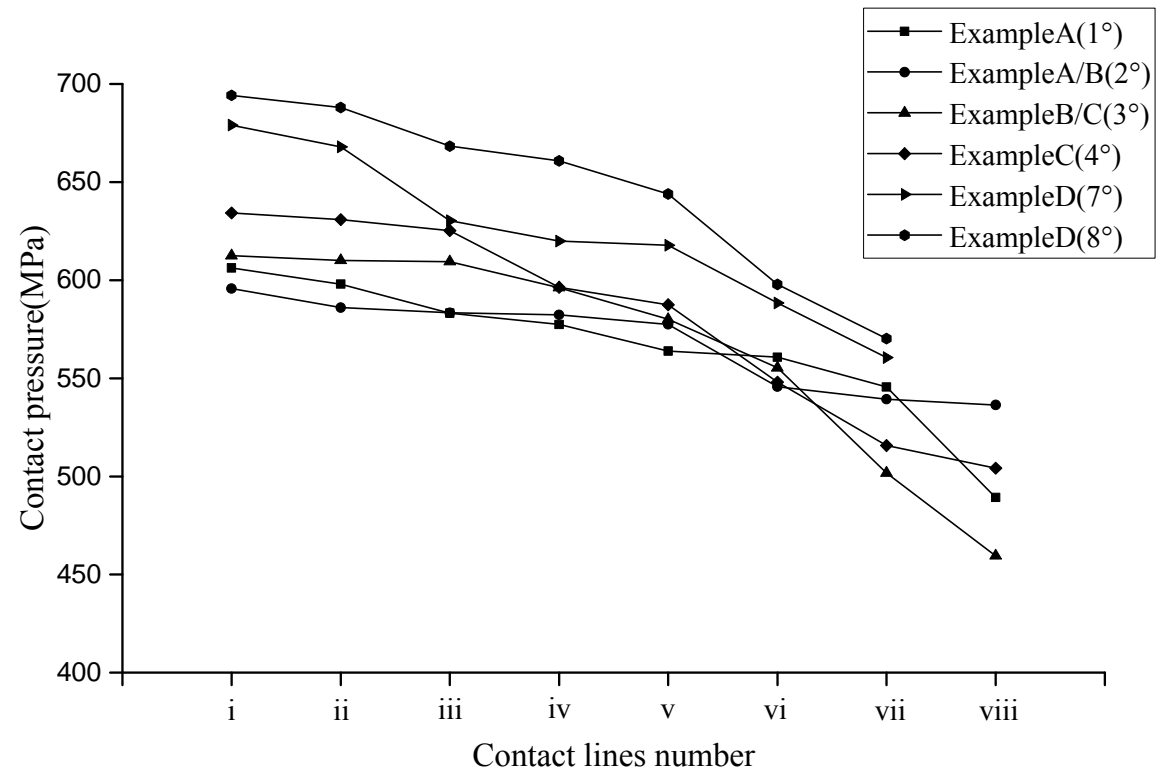

Fig. 12. Contact pressure of each contact lines

\section{Conclusions}

Presented is a precision-power hourglass worm drive via a TI worm meshing with an IHB gear. According on the performed research, the following conclusions might be drawn:

(1) A novel hourglass worm drive characterizes with backlash-adjustable and wear-compensable is proposed. It is consisted of an IHB gear and a TI worm generated by the IHB gear tooth surface, and the material of IHB gear is bearing steel, as well as the material of TI worm is structural steel.

(2) The meshing geometry of this hourglass worm drive is presented, and the theory of backlashadjustable and wear-compensable is confirmed by the careful geometrical study.

(3) Through the careful tooth contact analysis of the conjugate surface, with smaller helical angles comes bigger actual meshing area and more simultaneously contact teeth. 
(4) The high-loading capacity of this hourglass worm drive is confirmed by the meshing quality analysis and the stress analysis.

\section{Acknowledgment}

This work was supported by the National Natural Science Foundation of China (Grant No. 51405394 and No. 51575059), the Fundamental Research Funds of the State Key Laboratory of Mechanical Transmission, Chongqing University (No. SKLMT-ZZKT-2016T01 and No. SKLMT-ZZKT-2015Z09), the Fundamental Research Funds for the Central Universities (No. 106112016CDJXY110001).

\section{Nomenclature}

$a \quad$ Center distance of the worm drive, $(\mathrm{mm})$

$Z_{1}, Z_{2} \quad$ Number of the TI worm threads and the IHB gear teeth, respectively

$r_{\mathrm{b}} \quad$ Radius of the basic circle, $(\mathrm{mm})$

$m_{\mathrm{t}} \quad$ Transverse module, $(\mathrm{mm})$

$l \quad$ Effective length of the TI worm, (mm)

$b \quad$ Width of the IHB gear, (mm)

$\delta \quad$ Half-angle of tooth on the base circle, $\left({ }^{\circ}\right)$

$\beta \quad$ Inclination angle of the generating plane, $\left({ }^{\circ}\right)$

$i_{12} \quad$ Gearing ratio of the worm drive, here $i_{12}=Z_{2} / Z_{1}$

$\sigma_{\mathrm{m}}, \sigma_{\mathrm{n}} \quad$ Fixed coordinate systems

$\sigma_{1}, \sigma_{2} \quad$ Movable coordinate systems

$\sigma_{\mathrm{a}} \quad$ Auxiliary coordinate system

$\omega_{1}, \omega_{2} \quad$ Angular velocity vectors of the IHB gear and the TI worm, respectively, $(\mathrm{rad} / \mathrm{s})$

$\varphi_{1}, \varphi_{2} \quad$ Rotating angles of the IHB gear and the TI worm, respectively, $\left({ }^{\circ}\right)$

$\Sigma^{1}, \Sigma^{2} \quad$ Tooth surface of the IHB gear and the TI worm, respectively

$\boldsymbol{r}^{\mathrm{L}}, \boldsymbol{r}^{\mathrm{R}} \quad$ Position vector of the left flank and the right flank, respectively

$\beta_{\mathrm{L}}, \beta_{\mathrm{R}} \quad$ Helical angles on reference circle of the left flank and the right flank, respectively, $\left({ }^{\circ}\right)$

$\boldsymbol{v}_{12} \quad$ Relative velocity vector between planar IHB gear and TI worm, $(\mathrm{mm} / \mathrm{s})$

$\boldsymbol{n}_{1} \quad$ Unit normal vector of $\Sigma_{1}$

$\Phi, \Phi_{t}, \Psi \quad$ Function of meshing, meshing limit and undercutting limit, respectively

Normal vector of the contact line on meshing point in $\sigma_{1}$

$k_{\mathrm{\rho}} \quad$ Induced principal curvature, $\left(\mathrm{mm}^{-1}\right)$

$\theta_{\mathrm{v}} \quad$ Sliding angle, $\left({ }^{\circ}\right)$

$\Delta \quad$ Backlash between the IHB worm tooth surface and the TI worm tooth surface, $(\mathrm{mm})$

$h \quad$ Translational moving displacement of the IHB gear, $(\mathrm{mm})$ 


\section{References}

Buckingham, E., Analytical mechanics of gears, New York, Mcgraw-hill Book Company,INC., (1949), pp.225-237.

Chen, K. Y. and Tsay, C. B., Mathematical model and worm wheel tooth working surfaces of the ZN-type hourglass worm gear set, Mechanism and Machine Theory, Vol. 44, No.9(2009), pp.1701-1712.

Chen, Y. H., Zhang, G. H., Chen, B. K., Luo, W. J., Li, F. J. and Chen, Y., A novel enveloping worm pair via employing the conjugating planar internal gear as counterpart, Mechanism and Machine Theory, Vol. 67(2013), pp.17-31.

Chen, Y. H., Chen, Y., Wang, J. G. and Zhang, G. H., Manufacturing and measuring investigation of crown worm tooth surface, Journal of Advanced Mechanical Design Systems and Manufacturing, Vol. 9, No. 1(2015), DOI: 10.1299/jamdsm.2015jamdsm0003.

Chen, Y. H., Chen, Y., Luo, W. J. and Zhang, G. H., Development and classification of worm drive, 14th World Congress in Mechanism and Machine Science, Taipei, Taiwan, 25-30 October, 2015.

Crosher, W. P., Design and application of the worm gear, New York, ASME Press(2002), pp.15-17.

Deng, X. Q., Wang, J. G., Horstemeyer, M. F., Solanki, K. N. and Zhang, J. F., Parametric study of meshing characteristics with respect to different meshing rollers of the antibacklash double-roller enveloping worm gear, ASME Journal of Mechanical Design, Vol.134, No.8(2012), pp.1-12.

Dong, X. Z., Design and modification of hourglass worm drive(in Chinese), Beijing, Machinery Industry Press(2004), pp.39-67.

Dudás, I., The theory and practice of worm gear drives, London, Penton Press(2000), pp.5-23.

Fuentes, A., Jose, L. I., Ignacio, G. P. and Francisco, T. S., Computerized design of advanced straight and skew bevel gears produced by precision forging, Computer Methods in Applied Mechanics and Engineering, Vol.200 (2011), pp.2363-2377.

Fuentes, A., Ramon, R. O. and Ignacio, G. P., Computerized design simulation of meshing and finite element analysis of two types of geometry of curvilinear cylindrical gears, Computer Methods in Applied Mechanics and Engineering, Vol.272 (2014), pp.321-339.

Karpuschewski, B., Knoche, H. and Hipke, M., Gear finishing by abrasive processes, CIRP Annals - Manufacturing Technology, Vol. 57(2008), pp. 621-640.

Litvin, F. L. and A. Fuentes., Gear geometry and applied theory, second edition, New York, Cambridge University Press(2004), pp.183-232.

Maki, M., Okamoto, K. and Midorikawa, I., A study on the hourglass worm gearing whose wheel has the helical teeth(1st report), Transactions of the Japan Society of Mechanical Engineers, Part C, Vol.6, No.1582(1995), pp.362-366.

Mohan, L. V. and Shunmugam, M. S., Geometrical aspects of double enveloping worm gear drive, Mechanism and Machine Theory, Vol.44, No.11 (2009), pp.2053-2065.

Niemann, G. Maschinenelemente Band 2, New York, Springer(1965), pp.65-68.

Okamoto, K. and Maki, M., A study on the hourglass worm gearing whose wheel has the helical teeth(2nd report), Transactions of the Japan Society of Mechanical Engineers, Part C, Vol.62, No.601(1996), pp.3642-3646.

Sun, Y. H., Lu, H. W., Yang, W. Y. and Li, G. Y., A study on manufacture and experiment of hardened TI worm gearing(in Chinese), Chinese Journal of Mechanical Engineering, Vol.47, No.9(2011), pp. 182-186.

Wang, S. R., Zhan, D. A., Liu, H and Wang, S. Y., Tooth contact analysis of toroidal involute worm mating with involute 
helical gear, Mechanism and Machine Theory, Vol.37 (2002), pp.685-691.

Wildhaber, E., Wildhaber worm drive, United States Patent 3386305(1966).

Wu, D. R. and Luo, J. Y., Gear meshing theory, Beijing, Science Press(1985), pp.85-86.

Wu, X. T., Gear meshing theory,second edition, Xi'an, Xi'an Jiaotong University Press(2008), pp.129-131.

Zhang, G. H. and Li, Y. Y., Virtual center hourglass worm NC grinder(in Chinese). China Patent Licensing(2007).

Zhang, G. H., Research and application of planar double-enveloping hourglass worm drive(in Chinese), Journal of Chongqing University, (1978), pp.1-18.

Zhao, Y. P., Kong, J. Y. Li, G. F. and Wu,T. C., Tooth flank modification theory of dual-torus double-enveloping hourglass worm drives. Computer-Aided Design, Vol.43(2011), pp. 1535-1544.

Zhao, Y. P., Kong, J. Y. Li, G. F., Wu,T. C. and Shi, W. Y., Computerized simulation of tooth contact and error sensitivity investigation for ease-off hourglass worm drives, Computer-Aided Design, Vol. 44(2012), pp.778-790.

Zhao, Y. P. and Zhang, Z., Computer aided analysis on the meshing behavior of a height-modified dual-torus doubleenveloping toroidal worm drive, Computer-Aided Design, Vol.42(2010), pp.1232-1240. 